\title{
CORRECTION
}

\section{Correction to: Are religious investors financially smart? Evidence from equity funds}

\author{
Murat Yaş ${ }^{1}$. Ahmet Faruk Aysan ${ }^{2}\left(\mathbb{D} \cdot\right.$ Mohamed Eskandar Shah Mohd Rasid $^{3}$
}

Published online: 19 December 2021

(c) Springer Nature Limited 2021

\begin{abstract}
After publication, it was noticed that the sentence "2irardandHassan(2007om day1nforfunds in1990s" was introduced in the equations 3,4 and 5 by mistake. It should be removed from the equations 3,4 and 5 . The original article will be updated accordingly.
\end{abstract}

Publisher's Note Springer Nature remains neutral with regard to jurisdictional claims in published maps and institutional affiliations.

The original article can be found online at https://doi.org/10.1057/ s41260-021-00240-2.

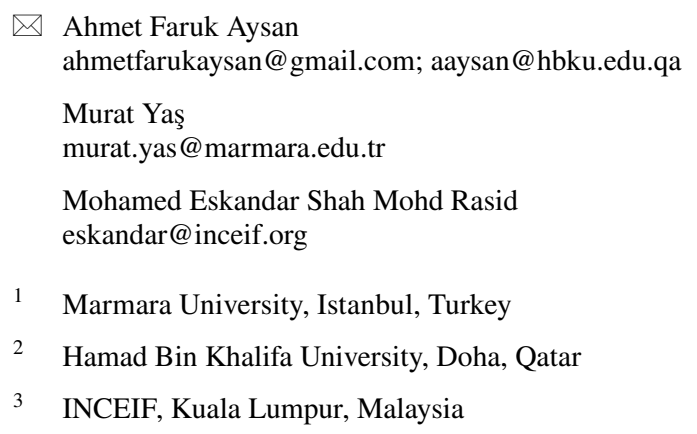

3 INCEIF, Kuala Lumpur, Malaysia 